\title{
Pathogenic Leptospira: Advances in understanding the molecular pathogenesis and virulence
}

\author{
Ciamak Ghazaei* \\ Department of Microbiology, University of Mohaghegh Ardabili, P.O. Box 179, Ardabil, Iran
}

\begin{abstract}
Leptospirosis is a common zoonotic disease has emerged as a major public health problem, with developing countries bearing disproportionate burdens. Although the diverse range of clinical manifestations of the leptospirosis in humans is widely documented, the mechanisms through which the pathogen causes disease remain undetermined. In addition, leptospirosis is a much-neglected life-threatening disease although it is one of the most important zoonoses occurring in a diverse range of epidemiological distribution. Recent advances in molecular profiling of pathogenic species of the genus Leptospira have improved our understanding of the evolutionary factors that determine virulence and mechanisms that the bacteria employ to survive. However, a major impediment to the formulation of intervention strategies has been the limited understanding of the disease determinants. Consequently, the association of the biological mechanisms to the pathogenesis of Leptospira, as well as the functions of numerous essential virulence factors still remain implicit. This review examines recent advances in genetic screening technologies, the underlying microbiological processes, the virulence factors and associated molecular mechanisms driving pathogenesis of Leptospira species.
\end{abstract}

Keywords: Leptospirosis, Molecular techniques, Pathogenesis, Virulence.

\section{Introduction}

Leptospirosis, a widespread zoonosis, has emerged as public health concern in both developed (Centers for Disease and Prevention, 1998; Benschop et al., 2009; Desai et al., 2009), and developing countries, as well as in tropical regions (Bharti et al., 2003; McBride et al., 2005; Riley et al., 2007), with the latter populations being hardest hit. Despite its significance at the global scene and severity, information on the molecular mechanisms of the pathogenesis, the evolution of virulence and related factors of Leptospira species remains limited.

The genus Leptospira responsible for causing leptospirosis is classified under the order Spirochaetales, and is further sub-divided into three species namely saprophytic (such as the Leptospira biflexa), pathogenic (Leptospira interrogans) and hostdependent (Leptospira borgpetersenii) (McBride et al., 2005; Lehmann et al., 2014). The infectious Leptospira exhibit specific affinities for the mammalian host, but display variations in adaptation to specific hosts (McBride et al., 2005).

Exposure to pathogenic Leptospira species in various environments cause general illnesses in a susceptible host (Faine et al., 1999; Levett, 2001). Reservoirs for Leptospira include both wild and domestic animals, and they target and persist mainly in their renal passage and are expelled through the urinary system (Bharti et al., 2003). Livestock and other animals that get infected often suffer fatal loss and acute kidney dysfunction, compounded by injury to the liver and lungs following an immune response mounted to defend the host against the pathogen (Faine et al., 1999; Levett, 2001). Humans are infected when they directly or indirectly come into contact with urinary products of infected animal reservoirs, making them unintentional and terminal susceptible hosts. In humans, infectious leptospirosis presents with varied clinical manifestations that range from mild self-limiting incidences to severe disease that can cause mortality (Faine et al., 1999; Levett, 2001). A severe disease is characterized by multi-organ damage that includes acute renal and hepatic failure, pulmonary distress, hemorrhage and jaundice, some of which can cause death, if left untreated (Faine et al., 1999; Bharti et al., 2003; Herrmann-Storck et al., 2010).

Leptospirosis is widely distributed geographically, and can be found in settings with varied epidemiology, such as rural and urban regions of tropical/subtropical climates and temperate regions of the world (Levett, 2001). Occupational exposure accounts for the majority of disease cases reported in developed countries (Benschop et al., 2009; Desai et al., 2009), often associated with tourism or sporting activities (Morgan et al., 2002; Stern et al., 2010). In contrast, developing countries carry the major burden of the disease, that affects vulnerable populations, such as subsistence farmers in the rural areas and slum residents in urban

*Corresponding Author: Ciamak Ghazaei. Department of Microbiology, University of Mohaghegh Ardabili, P.O. Box 179, Ardabil, Iran. Tel.: +98 045-33512081-9; Fax: +98 045-33510803. Email: ciamakghazaei@yahoo.com 
settings (Torgerson et al., 2015). In the year 2015, analysis of the Disability Adjusted Life Years (DALYs) lost following infections caused by pathogenic Leptospira were estimated at 2.90 million DALYs per annum (UIs 1.25-4.54 million), a nearly two-fold increase from previous year's reports (Torgerson et al., 2015). Interestingly, the males accounted for approximately $80 \%(\sim 2.33$ million $)$ of the total disease burden. The tropical regions of the world in the Asian, Americas and African continents were reported to have the highest estimates of leptospirosis disease burden (Torgerson et al., 2015).

Leptospira species are highly motile spirochetes with thin, slow-growing characteristics (Yanagawa and Faine, 1966) whose unique helical shape (Paster and Dewhirst, 2000). The cell morphology of Leptospira is determined by the layers of the cytoskeleton and murein proteins (Slamti et al., 2011) and confirmed by cryo-electron tomographical techniques (Raddi et al., 2012). A recent study identified a novel $36-\mathrm{kDa}$ Leptospira protein, shown to be the main component of the spirochete's periplasmic flagella (PF) sheath (Wunder et al., 2016). This protein, named the Flagellar-coiling protein A (FcpA), was shown to determine the coiled structure of the bacterial flagella and appeared to be an abundant protein on the $L$. interrogans PF surface (Wunder et al., 2016). Additional analysis of the gene that codes for the FcpA protein revealed a highly conserved consensus region among Leptospira, a characteristic that was not seen in other bacteria (Wunder et al., 2016). Analysis of the $(F c p A(-))$ mutants generated for the FcpA showed loss of potential to cause leptospirosis in animal models. However, addition of a viable FcpA to complement the mutant was shown to restore the morphology of the wild-type species as well as the phenotypes for motility and virulence (Wunder et al., 2016). These studies suggest a central role of the FcpA protein in the ability of the bacteria to translocate, infiltrate the host, cross tissue barriers to target organs and cause systemic infections (Wunder et al., 2016). Overall, these studies show that the morphological orientation of the flagella coiling protein modulates Leptospira infectivity.

Numerous studies have investigated the phylogeny of pathogenic and non-pathogenic Leptospira (Ravishankar et al., 2014; Fouts et al., 2016; Gomard et al., 2016). A recent detailed analysis of 20 genome sequences of isolates representing 20 of the 22 known Leptospira species was used to estimate the phylogenetic distances between species (Fouts et al., 2016). The results revealed clustering of the species into three groups, namely pathogenic, intermediately pathogenic and non-pathogenic (saprophytes) (Fouts et al., 2016). These results confirmed the genetic relatedness among Leptospira species as previously established by DNA hybridization (DDH) techniques
(Ramadass et al., 1992; Brem et al., 1999; Bourhy et al., 2014). Collectively, these results suggest lower variability within species across Leptospira genomes.

\section{Mechanisms of Pathogenesis \\ Biological Mechanisms}

The last decade has seen a plethora of studies (Fernandes et al., 2016; Gomard et al., 2016; Vieira and Nascimento, 2016) and reviews (Murray et al., 2009; Evangelista and Coburn, 2010; Adler et al., 2011) aimed at understanding the biology of Leptospira and disease pathogenesis mechanisms in leptospirosis, which is still is not well defined. A recent study showed that the persistence of the bacteria in an aqueous environment is mediated by a pathogenic Leptospiral protein encoding gene (lipL32) (Vinod Kumar et al., 2016). Additional studies described the mechanisms for the pathogen adaptation to thermal conditions (Eshghi et al., 2015a,b) and tolerance (Petrosova and Picardeau, 2014) outside the mammalian host. In addition, the inflammatory cascades that cause clinical disease (Gasque and Jaffar-Bandjee, 2015; Volz et al., 2015), virulence related proteins factors (King et al., 2014), bacteria-host interactions (Lo et al., 2009; Vieira et al., 2012; Siqueira et al., 2013; Fernandes et al., 2015), organization of the cytoskeletal and cellular in the host protein (Schuller et al., 2015) and defense mechanisms by the host (Werts, 2010) by pathogenic Leptospira have been described. Recent studies also identified leucine-rich repeat proteins that are known to be epitopes mediating antigen interaction (Nitipan et al., 2013), immune response factors in lipoproteins on the outer membrane of L. interrogans (Lin et al., 2010), ion transport mechanisms (Wu et al., 2004) and amino acid metabolism (Krajewska et al., 2016). These results suggest tremendous progress in understanding the various mechanisms involved in the biological process of Leptospira species infections.

Previous investigations (Nascimento et al., 2004; Picardeau et al., 2008; Ko et al., 2009), and more recent analysis (Alt et al., 2015; Fouts et al., 2016; Vinod Kumar et al., 2016) have focused on genome and genetic technologies in an attempt to define the mechanisms that underlie the pathogenesis of Leptospira species. As such, mutant organisms that mimic leptospirosis have been generated, that have significantly enhanced the identification of metabolic systems such as amino acid synthesis (Louvel et al., 2005) utilized by Leptospira species. A recent extensive comparative genomic analysis study of the Genus Leptospira (Fouts et al., 2016) attempted to identify changes that are localized in pathogenic Leptospira and provides an overall and important strategy in understanding leptospirosis. The analyses also provides previews into potential mechanisms adopted by bacteria to thrive in mammalian hosts (Fouts et al., 2016). Additional horizontal gene transfer 
and gene duplication studies conducted recently attempted to describe the process through which pathogenic Leptospira acquire virulence factors (Xu et al., 2016). These studies also described the virulencerelated protein families that showed virulence characteristics, and paralogs associated with metalloproteases-found only in pathogenic Leptospira (Xu et al., 2016). Putting together, these results show that there are genetic determinants in infectious species and clades of Leptospira that mediate mechanisms through which pathogenesis occurs and that these unique genes and gene variants are not found in noninfectious Leptospira species.

\section{Determinant of Leptospira Pathogenesis}

Numerous previous studies (Masuzawa et al., 1996; Park et al., 1999; Vedhagiri et al., 2009), and more recent efforts (Dietrich et al., 2015; Fontana et al., 2016) have been made to understand the determinants that underlie the pathogenesis of Leptospira species. Findings of a recent study on $L$. interrogans identified FliM protein that was shown to mediate the correct conformational structure of the bacteria through a complete and accurate formation of the flagella, the ability to translocate and target host cells and modulate virulence (Fontana et al., 2016). Additionally, a variety of genes that code for the outer membrane lipoproteins (ompL) were identified, which when considered alongside antigenic determinants whose sequence vary at specific sites, were shown to alter the affinities on infectivity (Vedhagiri et al., 2009). Membrane lipoproteins had previously been shown to provide protection against Leptospira (Haake et al., 1999). Similarly, the sequence conservation of the heat shock protein 58 (Hsp58) among leptospires was significant in host humoral immune response (Park et al., 1999). However, the exact determinants that drive the sequence of events following Leptospira species infection are yet to be described fully.

Earlier investigations (Evangelista and Coburn, 2010; Chaemchuen et al., 2011; Domingos et al., 2012) and more recent studies (Fernandes et al., 2016; Gomard et al., 2016; Vieira and Nascimento, 2016) have described antigens that mediate host-pathogen interactions among Leptospira species. Recent genome analyses studies indicated that the leptospira characterized as pathogenic possess a number of genes that coded for proteins containing leucine-rich repeat (LRR) domains (Nitipan et al., 2013; Miras et al., 2015), presumed to be important in structural motifs of different host proteins (Miras et al., 2015). Interestingly, these characteristics were not observed in saprophytes. In addition, complex proteins were shown to be expressed during infection and were thought to mediate the interaction between the susceptible host and pathogenic L. interrogans (Domingos et al., 2015). However, contrasting observations were reported where minor variations in individual sets of proteins with potential physiological and pathological roles were documented (Buyuktimkin and Saier, 2015).

\section{Virulence Factors}

The factors associated with virulence of various Leptospira species are often surface proteins that are thought to mediate the interaction between the bacterium and the host tissues (McBride et al., 2005). Leptospiral virulence factors that have been extensively reviewed (Ko et al., 2009; Adler et al., 2011; Narayanavari et al., 2012) include, among others hemeoxygenase, OmpA-like Loa22 protein, lipopolysaccharides (LPS), various adhesion molecules, flagella morphology, hemolysins and sphingomyelinases, all thought to be important during infection (Narayanavari et al., 2012). However, their actual contributions to the overall virulence is not fully known. Additionally, although several proteins are secreted by Leptospira species, including degradative enzymes, there is no evidence of a specific protein secretion pathway for host interaction (Lourdault et al., 2011). However, other virulence factors support the pathogen's ability to move as well as acquire iron (Ko et al., 2009).

Recent studies have also shown that the mammalian cell entry (Mce) protein of pathogenic Leptospira species is a virulence factor containing a motif with three amino acid sequence represented by Arg-Gly-Asp (RGD), believed to be responsible for infection of susceptible host cells and animals (Cosate et al., 2016). Binding of $L$. interrogans Mce was also observed with the human leukocyte cell receptors alphaLbeta2 [(CD11a/CD18)-LFA-1] and alphaMbeta2 [(CD11b/CD18)-Mac-1], suggesting the participation of these proteins in the induction of host immune response (Cosate et al., 2016). These and other studies (Oliveira et al., 2010; Lehmann et al., 2013; King et al., 2014) suggest that virulence of pathogenic Leptospira is mediated by a combination of factors derived from both the pathogen and susceptible host.

\section{Molecular Advance in Leptospira Pathogenesis Genetic Studies}

Initial genetic studies in the 1990s relied on generation of Escherichia coli mutants through functional complementation techniques (Stamm et al., 1991), that enabled isolation and expression of several Leptospira genes (Stamm et al., 1991; Baril et al., 1992; Mitchison et al., 1997). In the absence of plasmid vector that could replicate pathogenic Leptospira, alternative strategies were employed (Girons et al., 2000; Bourhy et al., 2005). As such, models were developed that could generate a plasmid vector with the capacity to replicate independently in both $E$. coli and L. biflexa (Girons et al., 2000). However, the advent of progressive genetic manipulation techniques in the last decade saw generation of both saprophytic and pathogenic 
Leptospira strains systems by deletion of chromosomal genes using targeted (Louvel and Picardeau, 2007) and random (Bourhy et al., 2005; Louvel et al., 2005; Murray et al., 2009) mutagenesis and pathogenic gene disruptions by site-directed homologous recombination (Croda et al., 2008). These strategies allowed the emergence of series of transformation experiments that generated approximately 721 mutations affecting protein coding regions of 551 Leptospira species genes (Murray et al., 2009). Subsequently, in silico search for DNA repair pathways in Leptospira species identified genes essential during infection (Martins-Pinheiro et al., 2016), although chemical modification of nucleotide bases through alkylation reactions was observed (Martins-Pinheiro et al., 2016). These studies show potential gene transfer events in Leptospira species.

\section{Advances on Genomics of Leptospira}

The International Committee on Systematics of Prokaryotes, on advice of the incharge subcommittee for reviewing the taxonomy of Leptospiraceae endorsed the genome sequence comparison technologies to replace traditional methods to define species of Leptospira (Smythe et al., 2013). The Leptospira Genome Project commissioned in the year 2011, has generated significant whole genome information for a number of known Leptospira species (Ricaldi et al., 2012a; Alt et al., 2015; Lehmann et al., 2016). A recent study reported on genomes of 17 Leptospira species isolates, represented 8 pathogenic, 4 intermediate and 5 saprophytic (Fouts et al., 2016), results that concur with previous studies (Nascimento et al., 2004). Generally, the genomes were projected to contain a protein-coding sequence with an average length of 4,197 nucleotide base pairs per genome (Fouts et al., 2016). Further analysis identified genes and gene families that were specific for Leptospira species, and included those coding for sialic acid biosynthesis, pathogen-specific porphyrin metabolism and riboswitch-regulated cobalamin (B12) autotrophy, all constituting bacterial virulence factors (Fouts et al., 2016). Put together, this information further improves our understanding the genes and the pathways that modulate the pathogenesis of Leptospira species.

\section{Leptospira Genome}

Numerous studies have described the genome of Leptospira species (Alt et al., 2015; Martins-Pinheiro et al., 2016; Xu et al., 2016). Previous analysis classified approximately $45 \%(\mathrm{n}=10)$ of the known $(\mathrm{n}=22)$ Leptospira species (Bourhy et al., 2014), with over 300 whole genomes of Leptospira sequences published, most being those from L. interrogans (Nascimento et al., 2004; Alt et al., 2015). Recent sequence analysis of 102 isolates representing global sources revealed a high genomic variability among different Leptospira species, attributable to systems of adaptation to specific habitats and changes in the host environmental conditions (Xu et al., 2016). Additional microarray analysis of $L$. interrogans expressing approximately 3,359 of all Leptospiral predicted open reading frames (ORFs; 3667) showed 191 antigens eliciting immunoglobulin (Ig) $\mathrm{M}$ or $\mathrm{IgG}$ response, representing $5 \%$ of the whole proteome (Lessa-Aquino et al., 2015), with 14 significantly enriched categories, $50 \%$ of the which were immunoreactive antigens (Lessa-Aquino et al., 2015).

Various previous studies have documented the $L$. interrogans transcript (Lo et al., 2010; Pinne et al., 2012; Iraola et al., 2016). Recent investigations generated the Transcriptional Start Site (TSS) map of Leptospira species (Zhukova et al., 2017), results of which showed that a larger proportion $(2,866)$ of the primary TSS (pTSS) were predicted in the genome of L. interrogans. Interestingly, significant numbers of the pTSSs were located within the first 10 nucleotides from the start point of translation, observations that signify translational regions of Leptospiral species that display characteristic leaderless transcripts (Zhukova et al., 2017). Additional studies on the L. interrogans genome sequence identified two genes (LIC11122 and LIC 12287) that code for two novel proteins that were characterized and labeled as a sigma factor and a potential functional protein, respectively (Figueredo $e t$ al., 2017). Further, analyses of genome sequences of $L$. interrogans mined from databases identified two proteins (LIC10821 and LIC10064) predicted to be exposed on the surface and versatile adhesin thought to mediate the interaction of Leptospira to its susceptible host (Silva et al., 2016).

Genome sequencing analysis of a recently discovered L. weilii pathogenic strain L231 revealed a region in the genome spanning 4.2 M base pairs. The strain L231 genome constitutes a proportion of $0.4067 \mathrm{G}$ and $\mathrm{C}$ base pairs and contains greater than 4,700 open reading frames (Xu et al., 2017). In addition, the strain L231 genome was found to have a larger locus for the biosynthesis of lipopolysaccharides than similar species $L$. interrogans and $L$. borgpetersenii represented by pathogenic strains serovar Lai and Hardjobovis, respectively (Xu et al., 2017). These results suggest evolutionary diversity across species and serovars, probably attributable to environmental determinants of Leptospira disease.

\section{Molecular Characterization of Virulence factors}

A previous review focused on characterization of Leptospiral virulence factors identified over 900 genes unique to either L. interrogans or L. borgpetersenii, some of which potentially encoded virulenceassociated proteins (Adler et al., 2011). Multi genes that were identified but whose functions were not known seemed to be over-represented in specific genes that confer pathogenesis (Adler et al., 2011). In 
addition, the compounding absence of virulence factor homologues among the proteins of known function suggests that Leptospira possesses unique virulence mechanisms (Adler et al., 2011).

The generation of mutagens of pathogenic Leptospira species (Croda et al., 2008; Murray et al., 2009; Lambert et al., 2012a), has allowed the screening of defined mutants for attenuation of virulence mechanisms in animal infection models (Croda et al., 2008). These studies have enabled the identification of a range of virulence factors, which include lipopolysaccharide (Mitchison et al., 1997), flagella (Raddi et al., 2012; Fontana et al., 2016), heme oxygenase and the OmpA-family protein, Loa22 (Tettelin et al., 2008).

\section{Regulation of Virulence Genes}

Recent review articles have attempted to describe the genetic mechanisms of virulence genes of Leptospira species (Adler et al., 2011; Murray, 2015). However, a recent genome-wide analysis of 20 species of Leptospira observed only three types of alternative sigma $(\sigma)$ factors $(\sigma 54, \sigma \mathrm{F}, \sigma \mathrm{E})$, a number that was much less than that in E. coli genome (Fouts et al., 2016). Interestingly, all pathogenic species were observed to contain two $\sigma 54$ regulatory networks, LepA- $\sigma 54$ and LepB- $\sigma 54$, and saprophytic Leptospira only have LepA- $\sigma 54$ (Fouts et al., 2016), suggesting their potential role in survival for both pathogenic and saprophytic Leptospira in the natural environments (Fouts et al., 2016). Meanwhile, the LepA- 654 was shown to be involved in pathogenic species survival in the host. However, studies to investigate are warranted. On further analysis, Leptospira was observed to contain between 5 and 10 extra-cytoplasmic function sigma $(\mathrm{ECF} \sigma)$ factors; pathogenic Leptospira have 5 more ECF $\sigma$ factors than saprophytic species, consistent with complex species that characterize pathogenicity (Fouts et al., 2016). Although the activity of ECFo factors is often regulated by an anti- $\sigma$ factor (Davenport and Patil, 2012), both pathogenic and saprophytic Leptospira contain over $30 \mathrm{\sigma E}$ regulators, suggesting potential variety of signals recognized by pathogenic and saprophytic Leptospira (Ho and Ellermeier, 2012). A recent pan-genome analysis (Vernikos et al., 2015) revealed the presence of 1,764 and 17,477 genes for 20 Leptospira core- and pan-genome genomes, respectively (Fouts et al., 2016). In addition, the structural characteristics of the Leptospira pan-genome was predicted to be open with protein clusters (Fouts $e t$ al., 2016).

Comparative analysis of the distribution of protein functions for clusters common to both infectious and non-infectious Leptospira revealed a dominance of "mobile and extrachromosomal elements" in the pathogenic Leptospira genome (Fouts et al., 2016). Additional analysis revealed that that the genes encoding the biosynthesis of various prosthetic groups, transport carriers, cofactors, fatty acid and phospholipid metabolism were present in both pathogens and intermediate pathogens (Fouts et al., 2016). On the contrary, genes that were reported to be specific for saprophyte were represented by 10 out of the 16 categories that played a functional role (Fouts $e t$ al., 2016). Many of these genes were shown to be involved in metabolism, generation of energy, regulation of gene, signal transduction mechanisms, determination of the fate of proteins and various functions of the cell envelope and transport processes (Fouts et al., 2016). However, the mechanism(s) of virulence remain to be investigated and experimental studies of this gene family are warranted to further describe the processes leading to the development of leptospirosis.

Advances on Metabolomics of Leptospira Species

A recent study developed a metabolic network of Leptospira and compared members of both pathogenic, intermediary pathogenic and non-pathogenic clades (Fouts et al., 2016), following genomically-predicted strategies described previously (Fondi and Lio, 2015a,b). The recent analysis of metabolic pathways reveal differential variability between infectious and non-infectious Leptospira in the synthesis of vitamin and porphyrin (Fouts et al., 2016). These analyses showed that pathogenic $L$. interrogans contains a complete biosynthetic pathway for vitamin B12, which facilitates in vivo synthesis of B12 using L-glutamate as a precursor, a pathway that was absent in L. biflexa (Fouts et al., 2016). Only pathogenic Leptospira (L. interrogans and L. kmetyi) were predicted to have a complete pathway for the biosynthesis of folate, a potential adaptation strategy for survival in nutrientlimited niches within the mammalian host, as previously observed (Stalheim and Wilson, 1964; Shenberg, 1967). Previous metabolic network models of $L$. interrogans were observed to be deficient in Lglutamate oxidoreductase (Murachi and Tabata, 1987; Bohmer et al., 1989), but the model for L. biflexa that predicted greater networks for metabolic processes showed promise (Fouts et al., 2016), suggesting a potential mode for a pathogenic spirochete if curated and validated in a laboratory experiment.

Further analysis of pathway for the biosynthesis of cobalamin in Leptospira revealed that genes that code for the B12 autotrophy occurred only in pathogenic Leptospira (Fouts et al., 2016), suggesting that autotrophy facilitates mammalian infection by Leptospira irrespective of B12 sequestration by the host (Fouts et al., 2016). In addition, recent studies observed that Leptospira could detoxify reactive oxygen species, suggesting possible strategy to evade defense mechanisms by the host or adapt to the environment (Fouts et al., 2016). These results were further 
supported by the observation that pathogenic Leptospira contained a catalase and a putative catalase ortholog, while the saprophytes contained only a gene that codes for superoxide dismutase enzyme (Fouts $e t$ al., 2016).

\section{Advances on Proteomics of Leptospira}

Numerous studies have explored the role of extracellular matrix (ECM)-binding proteins in modulating the adhesion of Leptospira to mammalian host cells, movement of Leptospira in and through tissue interstitial, and advancing colonization processes (Eshghi et al., 2009; Picardeau, 2015; Schuller et al., 2015). Recently, a varied collection of ECM-binding proteins has been identified, suggesting cross-reaction of adhesion molecules that probably form part of invasion mechanisms of Leptospira (Fouts et al., 2016). Multi-functional putative adhesins that bind to the plasminogen were also characterized (Fernandes et al., 2014; Vieira et al., 2014; Domingos et al., 2015), although the role of environmental biotic or abiotic structures in the biology of saprophytes is still unclear (Fouts et al., 2016). Previous studies have documented Leptospira, PLA reducing $\mathrm{C} 3 \mathrm{~b}$ and human $\mathrm{IgG}$ deposition, thereby impairing opsonization and restricting complement antibacterial functions (Vieira et al., 2012). Analysis of complement evasion strategies have shown that binding of Leptospira to factor $(\mathrm{FH})$, factor $\mathrm{H}$-like protein (FHL-1) and $\mathrm{C} 4$ binding protein (C4BP) (Meri et al., 2005; Barbosa et al., 2009), as well as to complement regulators-binding proteins occur (Barbosa et al., 2010; CastiblancoValencia et al., 2012; Domingos et al., 2012). All these interactions are known to act through complement inhibitory mechanisms (Potempa and Potempa, 2012); the Lsa23 is a known multifunctional protein with a role in the virulence characteristics of Leptospira (Siqueira et al., 2013). Proteomics analysis has recently been employed to determine the immune evasion strategies through degradation of complement proteins (Fouts et al., 2016). A recent analysis reported a sequence (LIC13322) encoding a putative thermo-lysin associated with degradation of complement factors, indicating a role in immune evasion systems utilized by pathogenic Leptospiral strains (Barbosa et al., 2009; Fraga et al., 2014). These results suggest a dual system employed by pathogenic Leptospira, to evade the complement system, first being the acquisition of host complement inhibitors and degradation of complement components, either thorough PLG/PLA generation or by the presence of bacterial proteases (Fouts et al., 2016). Sialic acid cluster (Ricaldi et al., 2012b) were detected in most pathogenic Leptospira species, but not in intermediately pathogenic and saprophytes (Fouts et al., 2016), suggesting a potential role as a virulence determinant, consistent with previous studies (Ricaldi et al., 2012b).

\section{Advances on Transcriptomes of Leptospira}

Recent studies (Xue et al., 2013; Iraola et al., 2016; Schons-Fonseca et al., 2016) and reviews (Murray, 2015; Picardeau, 2015) have described the application of transcriptomic technologies to decipher mechanisms of Leptospira pathogenesis (Zhukova et al., 2017). Reports from the RNA-sequence technology that enabled the generation of the first transcriptome (Iraola et al., 2016) facilitated the investigation of changes in the transcript turnover that were associated with the biofilm growth and description of the functional Leptospira pathways (Ko et al., 2009). Furthermore, a recent analysis of the binding receptors for LexA and transcript turnover following stress associated with genotypic toxicity in L. interrogans (Schons-Fonseca et al., 2016), suggest that potential shifts in gene expression occur following DNA damage, thereby downregulating genes involved in cell growth and virulence, but upregulating genes involved in generation of gene mutations and recombination (Schons-Fonseca et al., 2016). In addition, a previous study described the potential role of iron metabolism in Leptospira (Louvel et al., 2005), and explained how the pathogen responds to oxidative stress (King et al., 2014). The results have collectively shown the potential of transcript analysis to determine the mechanisms utilized by Leptospira in causing disease.

\section{Molecular Mechanisms of Infection}

Consistent with previous studies on pathogenesis of Leptospira in the context of motility and chemotaxis (Lambert et al., 2012a; Wunder et al., 2016), a recent study observed that pathogenic, intermediate and saprophytic species of Leptospira have all the genes that encode functional flagella (Fontana et al., 2016) and are highly conserved within the genus, suggesting that both pathogenic and non-pathogenic Leptospira show homology in gene sequences encoding flagella apparatus and structure. In contrast, genes encoding chemotaxis proteins showed high diversity across different Leptospira species (Fouts et al., 2016), with some chemotaxis proteins being absent in some species, a factor accounting for differential chemotactic behaviors observed in pathogenic and saprophytic Leptospira (Lambert et al., 2012b). These results suggest that variability in genes encoding chemotaxis proteins may influence adaptation of Leptospira to specific environments, such as the capacity to infect a mammalian host.

Numerous studies have investigated the twocomponent sensory systems (TCSs) (Guerreiro et al., 2001; Eshghi et al., 2009; Vieira et al., 2012) of Leptospira species, often the characteristic of potential variability of ecological niches that these species encounter, as observed in other bacteria (Meri et al., 2005). Pathogenic Leptospira have fewer TCSs potentially associated with host adaptations. By 
contrast, a larger proportion of unique TCSs in intermediates and higher in saprophytes facilitates adaptation to varied wider range of environmental conditions. Pathogenic species encode more than 70 TCS genes, suggesting complexity of Leptospira signaling networks that are key to pathogen survival (Fouts et al., 2016), although verification experiments are required.

\section{Conclusion}

Leptospirosis has been reported to occur worldwide, and several risk factors have been associated with the disease in susceptible hosts. Significant proportion of resources and time have been invested in attempting to understand mechanisms of Leptospira pathogenesis. Although significant advances have been made in the past decade towards understanding the basis of the disease at the molecular and cellular level, challenges to deciphering the mechanisms persist. This review summarizes the advances made in research underlying the microbiological processes of pathogenic Leptospira. Further, results of various recent genomewide association studies are presented, outlining the phylogenetic relationship among 20 species of Leptospira, and demonstrating that infectious species and clades of Leptospira contain unique genes that are not found in non-infectious Leptospira.

Recent comparative analysis of genome sequences of 20 isolates out of the 22 known Leptospira revealed low variability within and across species. In addition, various studies have documented possible biological mechanisms of leptospirosis, and have identified genes encoding proteins and/or processes thought to play a role on pathogenesis, including environmental adaptation genes, interactions between the bacteria and host, activation of genes modulating virulence and host response. Further, various determinants and virulence factors of pathogenesis have been identified, such as motility and chemotactic factors.

Molecular analysis technologies have facilitated genetic studies of the Leptospira species. The classification of the species is now based on the Leptospiraceae genome sequence comparisons. As such, recent studies have identified novel genes and protein-coding sequence in Leptospira genomes, which have been inferred to play key roles in metabolic processes including sialic acid biosynthesis, pathogenspecific porphyrin metabolism and riboswitchregulated cobalamin (B12) autotrophy. In addition, various functional ORFs and associated immune response functions have been identified. Numerous virulence genes, and their regulation mechanisms have been inferred, with possible roles including survival in natural environments for both infectious and noninfectious Leptospira.

Furthermore, some metabolic pathways have been described, such as the porphyrin and vitamin biosynthetic pathways for pathogenic and nonpathogens Leptospira, where vitamin B12 de novo synthesis pathways in infectious $L$. interrogans were observed to be compromised. In addition, proteomics studies have identified key structural proteins including extracellular matrix (ECM)-binding proteins that facilitate adhesion and targeting of Leptospira to susceptible host cells. In addition, modes of action of immune evasion protein components, including the complement and immunoglobulin molecules have been described. Finally, transcription maps based on RNAseq technologies have been reported, and the mechanisms of gene regulation inferred, thereby highlighting the mechanisms used by Leptospira species to cause diseases in susceptible hosts.

These studies and results presented cumulatively show significant progress in our understanding of the molecular mechanisms that underlie the pathogenesis and virulence of Leptospira species. However, most of the results presented relied on analysis of pre-existing databases or newly generated genome sequences using in-silico, computational and inferred genetic and molecular analysis techniques. Although these techniques provide valuable information to aid our understanding of the molecular aspects of diseases pathogenesis, these inferences may not hold in vivo following host infections. As such, experimental studies to test these hypotheses, confirm and validate results presented should be prioritized. Importantly, attempts to develop animal models that mimic Leptospira disease status are warranted.

\section{Conflict of interest}

The authors declare that there is no conflict of interests.

\section{References}

Adler, B., Lo, M., Seemann, T. and Murray, G.L. 2011. Pathogenesis of leptospirosis: the influence of genomics. Vet. Microbiol. 153(1-2), 73-81.

Alt, D.P., Wilson-Welder, J.H., Bayles, D.O., Cameron, C., Adler, B. and Bulach, D.M. 2015. Complete Genome Sequence of Leptospira interrogans Serovar Bratislava, Strain PigK151. Genome. Announc. 3(3).

Barbosa, A.S., Abreu, P.A., Vasconcellos, S.A., Morais, Z.M., Goncales, A.P. and Silva, A.S. 2009. Immune evasion of leptospira species by acquisition of human complement regulator C4BP. Infect. Immun. 77(3), 1137-1143.

Barbosa, A.S., Monaris, D., Silva, L.B., Morais, Z.M., Vasconcellos, S.A., Cianciarullo, A.M. 2010. Functional characterization of LcpA, a surfaceexposed protein of Leptospira spp. that binds the human complement regulator C4BP. Infect. Immun. 78(7), 3207-3216.

Baril, C., Richaud, C., Fournie, E., Baranton, G. and Saint Girons, I. 1992. Cloning of dapD, aroD and 
asd of Leptospira interrogans serovar icterohaemorrhagiae, and nucleotide sequence of the asd gene. J. Gen. Microbiol. 138(1), 47-53.

Benschop, J., Heuer, C., Jaros, P., Collins-Emerson, J., Midwinter, A. and Wilson, P. 2009. Seroprevalence of leptospirosis in workers at a New Zealand slaughterhouse. N Z Med. J. 122(1307), 39-47.

Bharti, A.R., Nally, J.E., Ricaldi, J.N., Matthias, M.A., Diaz, M.M., Lovett, M.A., Levett, P.N., Gilman, R.H., Willig, M.R., Gotuzzo, E., Vinetz, J.M. and Peru-United States Leptospirosis Consortium. 2003. Leptospirosis: a zoonotic disease of global importance. Lancet Infect. Dis. 3(12), 757-771.

Bohmer, A., Muller, A., Passarge, M., Liebs, P., Honeck, H. and Muller, H.G. 1989. A novel Lglutamate oxidase from Streptomyces endus. Purification and properties. Eur. J. Biochem. 182(2), 327-332.

Bourhy, P., Collet, L., Brisse, S. and Picardeau, M. 2014. Leptospira mayottensis sp. nov., a pathogenic species of the genus Leptospira isolated from humans. Int. J. Syst. Evol. Microbiol. 64(Pt 12), 4061-4067.

Bourhy, P., Louvel, H., Saint Girons, I. and Picardeau, M. 2005. Random insertional mutagenesis of Leptospira interrogans, the agent of leptospirosis, using a mariner transposon. J. Bacteriol. 187(9), 3255-3258.

Brem, S., Gerhards, H., Wollanke, B., Meyer, P. and Kopp, H. 1999. 35 leptospira isolated from the vitreous body of 32 horses with recurrent uveitis (ERU)]. Berl. Munch. Tierarztl. Wochenschr. 112(10-11), 390-393.

Buyuktimkin, B. and Saier, M.H. 2015. Comparative genomic analyses of transport proteins encoded within the genomes of Leptospira species. Microb. Pathog. 88, 52-64.

Castiblanco-Valencia, M.M., Fraga, T.R., Silva. L.B., Monaris, D., Abreu, P.A. and Strobel, S. 2012. Leptospiral immunoglobulin-like proteins interact with human complement regulators factor $\mathrm{H}$, FHL1, FHR-1, and C4BP. J. Infect. Dis. 205(6), 9951004.

Centers for Disease and Prevention. 1998. Outbreak of acute febrile illness among athletes participating in triathlons--Wisconsin and Illinois, MMWR. Morb. Mortal. Wkly. Rep. 47(28), 585-588.

Chaemchuen, S., Rungpragayphan, S., Poovorawan, Y. and Patarakul, K. 2011. Identification of candidate host proteins that interact with LipL32, the major outer membrane protein of pathogenic Leptospira, by random phage display peptide library. Vet. Microbiol. 153(1-2), 178-185.

Cosate, M.R., Siqueira, G.H., de Souza, G.O., Vasconcellos, S.A. and Nascimento, A.L. 2016.
Mammalian cell entry (Mce) protein of Leptospira interrogans binds extracellular matrix components, plasminogen and beta2 integrin. Microbiol. Immunol. 60(9), 586-598.

Croda, J., Figueira, C.P., Wunder, E.A., Santos, C.S., Reis, M.G. and Ko, A.I. 2008. Targeted mutagenesis in pathogenic Leptospira species: disruption of the LigB gene does not affect virulence in animal models of leptospirosis. Infect. Immun. 76(12), 5826-33.

Davenport, T.H. and Patil, D. 2012. Data scientist. Harvard business review. 90(5), 70-76.

Desai, S., van Treeck, U., Lierz, M., Espelage, W., Zota, L. and Sarbu, A. 2009. Resurgence of field fever in a temperate country: an epidemic of leptospirosis among seasonal strawberry harvesters in Germany in 2007. Clin. Infect. Dis. 48(6), 691697.

Dietrich, M., Wilkinson, D.A., Benlali, A., Lagadec, E., Ramasindrazana, B. and Dellagi, K. 2015. Leptospira and paramyxovirus infection dynamics in a bat maternity enlightens pathogen maintenance in wildlife. Environ. Microbiol. 17(11), 4280-4289.

Domingos, R.F., Fernandes, L.G., Romero, E.C., De Morais, Z.M., Vasconcellos, S.A. and Nascimento, A.L. 2015. Novel Leptospira interrogans protein Lsa32 is expressed during infection and binds laminin and plasminogen. Microbiology 161(Pt 4), 851-864.

Domingos, R.F., Vieira, M.L., Romero, E.C., Goncales, A.P., De Morais, Z.M. and Vasconcellos, S.A. 2012. Features of two proteins of Leptospira interrogans with potential role in host-pathogen interactions. BMC Microbiol. 12, 50.

Eshghi, A., Cullen, P.A., Cowen, L., Zuerner, R.L. and Cameron, C.E. 2009. Global proteome analysis of Leptospira interrogans. J. Proteome. Res. 8(10), 4564-4578.

Eshghi, A., Henderson, J., Trent, M.S. and Picardeau, M. 2015a. Leptospira interrogans lpxD Homologue Is Required for Thermal Acclimatization and Virulence. Infect. Immun. 83(11), 4314-4321.

Eshghi, A., Pappalardo, E., Hester, S., Thomas, B., Pretre, G. and Picardeau, M. 2015b. Pathogenic Leptospira interrogans exoproteins are primarily involved in heterotrophic processes. Infect. Immun. 83(8):3061-3073.

Evangelista, K.V. and Coburn, J. 2010. Leptospira as an emerging pathogen: a review of its biology, pathogenesis and host immune responses. Future Microbiol. 5(9), 1413-1425.

Faine, S., Adler, B., Bolin, C. and Perolat, P. 1999. Leptospira and leptospirosis. Melbourne, Australia.

Fernandes, L.G., De Morais, Z.M., Vasconcellos, S.A. and Nascimento, A.L. 2015. Leptospira interrogans reduces fibrin clot formation by modulating human 
thrombin activity via exosite I. Pathog. Dis. 73(4). doi: 10.1093/femspd/ftv001.

Fernandes, L.G., Siqueira, G.H., Teixeira, A.R., Silva, L.P., Figueredo, J.M. and Cosate, M.R. 2016. Leptospira spp.: Novel insights into host-pathogen interactions. Vet. Immunol. Immunopathol. 176, 50-57.

Fernandes, L.G., Vieira, M.L., Alves, I.J., De Morais, Z.M., Vasconcellos, S.A. and Romero E.C. 2014. Functional and immunological evaluation of two novel proteins of Leptospira spp. Microbiology 160(Pt 1), 149-164.

Figueredo, J.M., Siqueira, G.H., De Souza, G.O., Heinemann, M.B., Vasconcellos, S.A. and Chapola, E.G. 2017. Characterization of two new putative adhesins of Leptospira interrogans. Microbiology 163(1), 37-51.

Fondi, M. and Lio, P. 2015a. Genome-scale metabolic network reconstruction. Methods Mol. Biol. 1231, 233-56.

Fondi, M. and Lio, P. 2015b. Multi -omics and metabolic modelling pipelines: challenges and tools for systems microbiology. Microbiol. Res. 171, 5264.

Fontana, C., Lambert, A., Benaroudj, N., Gasparini, D., Gorgette, O. and Cachet, N. 2016. Analysis of a Spontaneous Non-Motile and Avirulent Mutant Shows That FliM Is Required for Full Endoflagella Assembly in Leptospira interrogans. PLoS One. 11(4), e0152916.

Fouts, D.E., Matthias, M.A., Adhikarla, H., Adler, B., Amorim-Santos, L. and Berg, D.E. 2016. What Makes a Bacterial Species Pathogenic?: Comparative Genomic Analysis of the Genus Leptospira. PLoS Negl. Trop. Dis. 10(2):e0004403.

Fraga, T.R., Courrol Ddos, S., Castiblanco-Valencia, M.M., Hirata, I.Y., Vasconcellos, S.A. Juliano, L., Barbosa, A.S. and Isaac, L. 2014. Immune evasion by pathogenic Leptospira strains: the secretion of proteases that directly cleave complement proteins. J. Infect Dis. 209(6), 876-886.

Gasque, P. and Jaffar-Bandjee, M.C. 2015. The immunology and inflammatory responses of human melanocytes in infectious diseases. J. Infect. 71(4), 413-421.

Girons, I.S., Bourhy, P., Ottone, C., Picardeau, M., Yelton, D., Hendrix, R.W., Glaser, P. and Charon, N. 2000. The LE1 bacteriophage replicates as a plasmid within Leptospira biflexa: construction of an L. biflexa-Escherichia coli shuttle vector. J. Bacteriol. 182(20), 5700-5705.

Gomard, Y., Dietrich, M., Wieseke, N., Ramasindrazana, B., Lagadec, E. and Goodman, S.M., 2016. Malagasy bats shelter a considerable genetic diversity of pathogenic Leptospira suggesting notable host-specificity patterns. FEMS
Microbiol. $\quad$ Ecol. 92(4), doi: 10.1093/femsec/fiw037.

Guerreiro, H., Croda, J., Flannery, B., Mazel, M., Matsunaga, J. and Galvao Reis, M. 2001. Leptospiral proteins recognized during the humoral immune response to leptospirosis in humans. Infect. Immun. 69(8), 4958-4968.

Haake, D.A., Mazel, M.K., McCoy, A.M., Milward, F., Chao, G. and Matsunaga, J. 1999. Leptospiral outer membrane proteins OmpL1 and LipL41 exhibit synergistic immunoprotection. Infect. Immun. 67(12), 6572-6582.

Herrmann-Storck, C., Saint-Louis, M., Foucand, T., Lamaury, I., Deloumeaux, J. and Baranton G. 2010. Severe leptospirosis in hospitalized patients, Guadeloupe. Emerg. Infect. Dis. 16(2), 331-334.

Ho, T.D. and Ellermeier, C.D. 2012. Extra cytoplasmic function sigma factor activation. Curr. Opin. Microbiol. 15(2), 182-188.

Iraola, G., Spangenberg, L., Lopes Bastos, B., Grana, M., Vasconcelos, L. and Almeida, A. 2016. Transcriptome Sequencing Reveals Wide Expression Reprogramming of Basal and Unknown Genes in Leptospira biflexa Biofilms. mSphere. 1(2), e00042.

King, A.M., Pretre, G., Bartpho, T., Sermswan, R.W., Toma, C. and Suzuki, T. 2014. High-temperature protein $G$ is an essential virulence factor of Leptospira interrogans. Infect. Immun. 82(3), 11231131.

Ko, A.I., Goarant, C. and Picardeau, M. 2009. Leptospira: the dawn of the molecular genetics era for an emerging zoonotic pathogen. Nat. Rev. Microbiol. 7(10), 736-747.

Krajewska, J., Arent, Z., Wieckowski, D., Zolkiewski, M. and Kedzierska-Mieszkowska, S. 2016. Immunoreactivity of the AAA+ chaperone $\mathrm{ClpB}$ from Leptospira interrogans with sera from Leptospira-infected animals. BMC Microbiol. 16(1), 151.

Lambert, A., Picardeau, M., Haake, D.A., Sermswan, R.W., Srikram, A. and Adler, B. 2012a. FlaA proteins in Leptospira interrogans are essential for motility and virulence but are not required for formation of the flagellum sheath. Infect. Immun. 80(6), 2019-25.

Lambert, A., Takahashi, N., Charon, N.W. and Picardeau, M. 2012b. Chemotactic behavior of pathogenic and nonpathogenic Leptospira species. Appl. Environ. Microbiol. 78(23):8467-9.

Lehmann, J.S., Corey, V.C., Ricaldi, J.N., Vinetz, J.M., Winzeler, E.A. and Matthias, M.A. 2016. Whole Genome Shotgun Sequencing Shows Selection on Leptospira Regulatory Proteins During in vitro Culture Attenuation. Am. J. Trop. Med. Hyg. 94(2), 302-313. 
Lehmann, J.S., Fouts, D.E., Haft, D.H., Cannella, A.P., Ricaldi, J.N. and Brinkac, L. 2013. Pathogenomic inference of virulence-associated genes in Leptospira interrogans. PLoS Negl. Trop. Dis. 7(10), e2468.

Lehmann, J.S., Matthias, M.A., Vinetz, J.M. and Fouts, D.E. 2014. Leptospiral pathogenomics. Pathogens 3(2), 280-308.

Lessa-Aquino, C., Wunder, E.A., Lindow, J.C., Rodrigues, C.B., Pablo, J. and Nakajima, R. 2015. Proteomic features predict seroreactivity against leptospiral antigens in leptospirosis patients. J. Proteome. Res. 14(1), 549-556.

Levett, P.N. 2001. Leptospirosis. Clin. Microbiol. Rev. 14(2), 296-326.

Lin, X., Zhao, J., Qian, J., Mao, Y., Pan, J. and Li, L. 2010. Identification of immunodominant B- and Tcell combined epitopes in outer membrane lipoproteins LipL32 and LipL21 of Leptospira interrogans. Clin. Vaccine Immunol. 17, 778-783.

Lo, M., Cordwell, S.J., Bulach, D.M. and Adler, B. 2009. Comparative transcriptional and translational analysis of leptospiral outer membrane protein expression in response to temperature. PLoS Negl. Trop. Dis. 3(12), e560.

Lo, M., Murray, G.L., Khoo, C.A., Haake, D.A., Zuerner, R.L. and Adler B. 2010. Transcriptional response of Leptospira interrogans to iron limitation and characterization of a PerR homolog. Infect. Immun. 78(11), 4850-4859.

Lourdault, K., Cerqueira, G.M., Wunder, E.A. and Picardeau, M. 2011. Inactivation of clpB in the pathogen Leptospira interrogans reduces virulence and resistance to stress conditions. Infect. Immun. 79(9), 3711-3717.

Louvel, H. and Picardeau, M. 2007. Genetic Manipulation of Leptospira biflexa. Current Protocols in Microbiology. Hoboken, N.J.: J Wiley and Sons; Hoboken, N.J.

Louvel, H., Saint Girons, I. and Picardeau, M. 2005. Isolation and characterization of FecA- and FeoBmediated iron acquisition systems of the spirochete Leptospira biflexa by random insertional mutagenesis. J. Bacteriol. 187(9), 3249-3254.

Martins-Pinheiro, M., Schons-Fonseca, L., Silva, J.B., Domingos, R.H., Momo, L.H. and Simoes, A.C. 2016. Genomic survey and expression analysis of DNA repair genes in the genus Leptospira. Mol. Genet. Genomics. 291(2), 703-722.

Masuzawa, T., Nakamura, R., Beppu, Y. and Yanagihara, Y. 1996. Immunochemical characteristics and localization on cells of protective antigen (PAg) prepared from Leptospira interrogans serovar lai. Microbiol. Immunol. 40(3), 237-241.
McBride, A.J., Athanazio, D.A., Reis, M.G. and Ko, A.I. 2005. Leptospirosis. Curr. Opin. Infect. Dis. 18(5), 376-386.

Meri, T., Murgia, R., Stefanel, P., Meri, S. and Cinco, M. 2005. Regulation of complement activation at the C3-level by serum resistant leptospires. Microb. Pathog. 39(4), 139-147.

Miras, I., Saul, F., Nowakowski, M., Weber, P., Haouz, A. and Shepard, W. 2015. Structural characterization of a novel subfamily of leucinerich repeat proteins from the human pathogen Leptospira interrogans. Acta. Crystallogr. D. Biol. Crystallogr. 71(Pt 6), 1351-1359.

Mitchison, M., Bulach, D.M., Vinh, T., Rajakumar, K., Faine, S. and Adler, B. 1997. Identification and characterization of the dTDP-rhamnose biosynthesis and transfer genes of the lipopolysaccharide-related rfb locus in Leptospira interrogans serovar Copenhageni. J. Bacteriol. 179(4), 1262-1267.

Morgan, J., Bornstein, S.L., Karpati, A.M., Bruce, M., Bolin, C.A., Austin, C.C., Woods, C.W., Lingappa, J., Langkop, C., Davis, B., Graham, D.R., Proctor, M., Ashford, D.A., Bajani, M., Bragg, S.L., Shutt, K., Perkins, B.A., Tappero, J.W. and Leptospirosis Working Group. 2002. Outbreak of leptospirosis among triathlon participants and community residents in Springfield, Illinois, 1998. Clin. Infect. Dis. 34(12), 1593-1599.

Murachi, T. and Tabata, M. 1987. Use of a bioreactor consisting of sequentially aligned L-glutamate dehydrogenase and L-glutamate oxidase for the determination of ammonia by chemiluminescence. Biotechnol. Appl. Biochem. 9(4), 303-309.

Murray, G.L., Morel, V., Cerqueira, G.M., Croda, J., Srikram, A. and Henry, R, 2009. Genome-wide transposon mutagenesis in pathogenic Leptospira species. Infect. Immun. 77(2), 810-816.

Murray, G.L. 2015. The molecular basis of leptospiral pathogenesis. Curr. Top. Microbiol. Immunol. 387, 139-185.

Narayanavari, S.A., Sritharan, M., Haake, D.A. and Matsunaga, J. 2012. Multiple leptospiral sphingomyelinases (or are there?). Microbiology 158(Pt 5), 1137-1146.

Nascimento, A.L., Ko, A.I., Martins, E.A., MonteiroVitorello, C.B., Ho, P.L. and Haake, D.A. 2004. Comparative genomics of two Leptospira interrogans serovars reveals novel insights into physiology and pathogenesis. J. Bacteriol. 186(7), 2164-2172.

Nitipan, S., Sritrakul, T., Kunjantarachot, A. and Prapong, S. 2013. Identification of epitopes in Leptospira borgpetersenii leucine-rich repeat proteins. Infect. Genet. Evol. 14, 46-57. 
Oliveira, T.R., Longhi, M.T., Goncales, A.P., De Morais, Z.M., Vasconcellos, S.A. and Nascimento, A.L. 2010. LipL53, a temperature regulated protein from Leptospira interrogans that binds to extracellular matrix molecules. Microbes Infect. 12(3), 207-217.

Park, S.H., Ahn, B.Y. and Kim, M.J. 1999. Expression and immunologic characterization of recombinant heat shock protein 58 of Leptospira species: a major target antigen of the humoral immune response. DNA Cell Biol. 18(12), 903-910.

Paster, B.J. and Dewhirst, F.E. 2000. Phylogenetic foundation of spirochetes. J. Mol. Microbiol. Biotechnol. 2(4), 341-344.

Petrosova, H. and Picardeau, M. 2014. Screening of a Leptospira biflexa mutant library to identify genes involved in ethidium bromide tolerance. Appl. Environ. Microbiol. 80(19), 6091-6103.

Picardeau, M., Bulach, D.M., Bouchier, C., Zuerner, R.L., Zidane, N. and Wilson, P.J., 2008. Genome sequence of the saprophyte Leptospira biflexa provides insights into the evolution of Leptospira and the pathogenesis of leptospirosis. PLoS One. $3(2)$, e1607.

Picardeau, M. 2015. Genomics, proteomics, and genetics of leptospira. Curr. Top. Microbiol. Immunol. 387, 43-63.

Pinne, M., Matsunaga, J. and Haake, D.A. 2012. Leptospiral outer membrane protein microarray, a novel approach to identification of host ligandbinding proteins. J. Bacteriol. 194(22), 6074-6087.

Potempa, M. and Potempa, J. 2012. Protease-dependent mechanisms of complement evasion by bacterial pathogens. Biol. Chem. 393(9), 873-888.

Raddi, G., Morado, D.R., Yan, J., Haake, D.A., Yang, X.F. and Liu, J. 2012. Three-dimensional structures of pathogenic and saprophytic Leptospira species revealed by cryo-electron tomography. J. Bacteriol. 194(6), 1299-1306.

Ramadass, P., Jarvis, B.D., Corner, R.J., Penny, D. and Marshall, R.B. 1992. Genetic characterization of pathogenic Leptospira species by DNA hybridization. Int. J. Syst. Bacteriol. 42(2), 215219.

Ravishankar, V., Ahmed, A., Sivagnanam, U., Muthuraman, K., Karthikaichamy, A. and Wilson, H.A. 2014. Evolution of the RNase P RNA structural domain in Leptospira spp. Res. Microbiol. 165(10), 813-825.

Ricaldi, J.N., Fouts, D.E., Selengut, J.D., Harkins, D.M., Patra, K.P., Moreno, A., Lehmann, J.S., Purushe, J., Sanka, R., Torres, M., Webster, N.J., Vinetz, J.M. and Matthias, M.A. 2012a. Whole genome analysis of Leptospira licerasiae provides insight into leptospiral evolution and pathogenicity. PLoS Negl. Trop. Dis. 6(10), e1853.
Ricaldi, J.N., Matthias, M.A., Vinetz, J.M. and Lewis, A.L. 2012b. Expression of sialic acids and other nonulosonic acids in Leptospira. BMC Microbiol. 12, 161. doi: 10.1186/1471-2180-12-161.

Riley, L.W., Ko, A.I., Unger, A. and Reis, M.G. 2007. Slum health: diseases of neglected populations. BMC Int Health Hum Rights. 7, 2. doi: 10.1186/1472-698X-7-2.

Schons-Fonseca, L., Da Silva, J.B., Milanez, J.S., Domingos, R.H., Smith, J.L. and Nakaya, H.I. 2016. Analysis of LexA binding sites and transcriptomics in response to genotoxic stress in Leptospira interrogans. Nucleic Acids Res. 44(3), 1179-1191.

Schuller, S., Sergeant, K., Renaut, J., Callanan, J.J., Scaife, C. and Nally, J.E. 2015. Comparative proteomic analysis of lung tissue from guinea pigs with leptospiral pulmonary haemorrhage syndrome (LPHS) reveals a decrease in abundance of host proteins involved in cytoskeletal and cellular organization. J. Proteomics. 122, 55-72.

Shenberg, E. 1967. Growth of pathogenic Leptospira in chemically defined media. J. Bacteriol. 93(5), 15981606.

Silva, L.P., Fernandes, L.G., Vieira, M.L., De Souza, G.O., Heinemann, M.B. and Vasconcellos, S.A. 2016. Evaluation of two novel leptospiral proteins for their interaction with human host components. Pathog. Dis. 74(5). doi: 10.1093/femspd/ftw040.

Siqueira, G.H., Atzingen, M.V., Alves, I.J., De Morais, Z.M., Vasconcellos, S.A. and Nascimento, A.L. 2013. Characterization of three novel adhesins of Leptospira interrogans. Am. J. Trop. Med. Hyg. 89(6), 1103-1116.

Slamti, L., de Pedro, M.A., Guichet, E. and Picardeau, M. 2011. Deciphering morphological determinants of the helix-shaped Leptospira. J. Bacteriol. 193(22), 6266-6275.

Smythe, L., Adler, B., Hartskeerl, R.A., Galloway, R.L., Turenne, C.Y. and Levett, P.N. 2013. Classification of Leptospira genomospecies 1, 3, 4 and 5 as Leptospira alstonii sp. nov., Leptospira vanthielii sp. nov., Leptospira terpstrae sp. nov. and Leptospira yanagawae sp. nov., respectively. Int. J. Syst. Evol. Microbiol. 63(Pt 5), 1859-1862

Stalheim, O.H. and Wilson, J.B. 1964. Cultivation of Leptospirae. I. Nutrition of Leptospira Canicola. J. Bacteriol. 88, 48-54.

Stamm, L.V., Parrish, E.A. and Gherardini, F.C. 1991. Cloning of the recA gene from a free-living leptospire and distribution of RecA-like protein among spirochetes. Appl. Environ. Microbiol. 57(1), 183-189.

Stern, E.J., Galloway, R., Shadomy, S.V., Wannemuehler, K., Atrubin, D. and Blackmore, C. 2010. Outbreak of leptospirosis among Adventure 
Race participants in Florida, 2005. Clin. Infect. Dis. 50(6), 843-849.

Tettelin, H., Riley, D., Cattuto, C. and Medini, D. 2008. Comparative genomics: the bacterial pan-genome. Curr. Opin. Microbiol. 11(5), 472-477.

Torgerson, P.R., Hagan, J.E., Costa, F., Calcagno, J., Kane, M. and Martinez-Silveira, M.S. 2015. Global Burden of Leptospirosis: Estimated in Terms of Disability Adjusted Life Years. PLoS Negl. Trop. Dis. 9(10), e0004122.

Vedhagiri, K., Natarajaseenivasan, K., Chellapandi, P., Prabhakaran, S.G., Selvin, J. and Sharma, S. 2009. Evolutionary implication of outer membrane lipoprotein-encoding genes ompL1, UpL32 and lipL41 of pathogenic Leptospira species. Genomics Proteomics Bioinformatics 7(3), 96-106.

Vernikos, G., Medini, D., Riley, D.R. and Tettelin, H. 2015. Ten years of pan-genome analyses. Curr. Opin. Microbiol. 23, 148-154.

Vieira, M.L., Atzingen, M.V., Oliveira, R., Mendes, R.S., Domingos, R.F. and Vasconcellos, S.A. 2012. Plasminogen binding proteins and plasmin generation on the surface of Leptospira spp.: the contribution to the bacteria-host interactions. J. Biomed. Biotechnol. 758513. doi: 10.1155/2012/758513.

Vieira, M.L., Fernandes, L.G., Domingos, R.F., Oliveira, R., Siqueira, G.H. and Souza, N.M. 2014. Leptospiral extracellular matrix adhesins as mediators of pathogen-host interactions. FEMS Microbiol. Lett. 352(2), 129-139.

Vieira, M.L. and Nascimento, A.L. 2016. Interaction of spirochetes with the host fibrinolytic system and potential roles in pathogenesis. Crit. Rev. Microbiol. 42(4), 573-587.

Vinod Kumar, K., Lall, C., Vimal Raj, R., Vedhagiri, K. and Vijayachari, P. 2016. Molecular detection of pathogenic leptospiral protein encoding gene (lipL32) in environmental aquatic biofilms. Lett. Appl. Microbiol. 62(4), 311-315.

Volz, M.S., Moos, V., Allers, K., Luge, E., MayerScholl, A. and Nockler, K. 2015. Specific CD4+ TCell Reactivity and Cytokine Release in Different Clinical Presentations of Leptospirosis. Clin.
Vaccine Immunol. 22(12), 1276-1284.

Werts, C. 2010. Leptospirosis: a Toll road from B lymphocytes. Chang Gung Med. J. 33(6), 591-601.

Wu, M.S., Yang, C.W., Pan, M.J., Chang, C.T. and Chen, Y.C. 2004. Reduced renal Na+-K+-Cl- cotransporter activity and inhibited NKCC2 mRNA expression by Leptospira shermani: from bed-side to bench. Nephrol. Dial. Transplant. 19(10), 24722479.

Wunder, E.A., Figueira, C.P., Benaroudj, N., Hu, B., Tong, B.A. and Trajtenberg, F. 2016. A novel flagellar sheath protein, FcpA, determines filament coiling, translational motility and virulence for the Leptospira spirochete. Mol. Microbiol. 101(3), 457470.

Xu, Y., Zheng, H., Zhang, Y., Wang, Y., Zhang, J., Li, Z., Cui, S., Xin, X., Ye, Q., Chang, Y.F. and Wang, J. 2017. Genomic Analysis of a New Serovar of Leptospira weilii Serogroup Manhao. Front. Microbiol. 8, 149. doi: 10.3389/fmicb.2017.00149.

Xu, Y., Zhu, Y., Wang, Y., Chang, Y.F., Zhang, Y., Jiang, X., Zhuang, X., Zhu, Y., Zhang, J., Zeng, L., Yang, M., Li, S., Wang, S., Ye, Q., Xin, X., Zhao, G., Zheng, H., Guo, X. and Wang, J. 2016. Whole genome sequencing revealed host adaptation-focused genomic plasticity of pathogenic Leptospira. Sci. Rep. 6:20020. doi: 10.1038/srep20020.

Xue, F., Zhao, X., Yang, Y., Zhao, J., Yang, Y., Cao, Y., Hong, C., Liu, Y., Sun, L., Huang, M. and Gu, J. 2013. Responses of murine and human macrophages to leptospiral infection: a study using comparative array analysis. PLoS Negl. Trop. Dis. 7(10), e2477. doi: 10.1371/journal.pntd.0002477.

Yanagawa, R. and Faine, S. 1966. Morphological and serological analysis of leptospiral structure. Nature 211(5051), 823-826.

Zhukova, A., Fernandes, L.G., Hugon, P., Pappas, C.J., Sismeiro, O., Coppee, J.Y., Becavin, C., Malabat, C., Eshghi, A., Zhang, J.J., Yang, F.X. and Picardeau, M. 2017. Genome-Wide Transcriptional Start Site Mapping and sRNA Identification in the Pathogen Leptospira interrogans. Front. Cell Infect. Microbiol. 7, 10. doi: 10.3389/fcimb.2017.00010. 